\title{
Multidisciplinary In-Depth Investigation in a Young Athlete Suffering from Syncope Caused by Myocardial Bridge
}

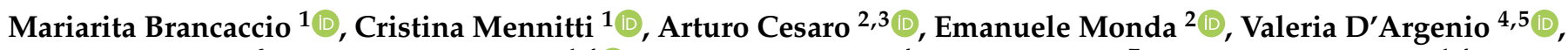 \\ Giorgio Casaburi ${ }^{6}$, Cristina Mazzaccara ${ }^{1,4}\left(\mathbb{0}\right.$, Annaluisa Ranieri ${ }^{4}$, Fabio Fimiani ${ }^{7}$, Ferdinando Barretta ${ }^{1,4}$, \\ Fabiana Uomo ${ }^{1,4}$, Martina Caiazza ${ }^{8}{ }^{-}$, Michele Lioncino ${ }^{2}$, Giovanni D'Alicandro ${ }^{9}$, Giuseppe Limongelli ${ }^{2}(\mathbb{D}$,

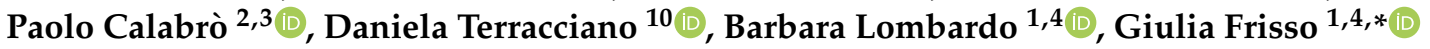 \\ and Olga Scudiero $1,4,11, * \mathbb{D}$
}

Citation: Brancaccio, M.; Mennitti, C.; Cesaro, A.; Monda, E.; D'Argenio, V.; Casaburi, G.; Mazzaccara, C.; Ranieri, A.; Fimiani, F.; Barretta, F.; et al. Multidisciplinary In-Depth Investigation in a Young Athlete Suffering from Syncope Caused by Myocardial Bridge. Diagnostics 2021, 11, 2144. https://doi.org/10.3390/ diagnostics11112144

Academic Editors: Lukasz Malek and Marek Postuła

Received: 29 September 2021 Accepted: 12 November 2021 Published: 19 November 2021

Publisher's Note: MDPI stays neutral with regard to jurisdictional claims in published maps and institutional affiliations.

Copyright: (c) 2021 by the authors. Licensee MDPI, Basel, Switzerland. This article is an open access article distributed under the terms and conditions of the Creative Commons Attribution (CC BY) license (https:/ / creativecommons.org/licenses/by/ $4.0 /)$.
1 Department of Molecular Medicine and Medical Biotechnology, University of Naples Federico II, 80131 Naples, Italy; brancacciomariarita2@gmail.com (M.B.); cristinamennitti@libero.it (C.M.); cristina.mazzaccara@unina.it (C.M.); barretta@ceinge.unina.it (F.B.); fa.uomo@studenti.unina.it (F.U.); barbara.lombardo@unina.it (B.L.)

2 Department of Translational Medical Sciences, Università degli Studi della Campania "Luigi Vanvitelli", 80138 Naples, Italy; arturocesaro@hotmail.it (A.C.); emanuelemonda@me.com (E.M.); michelelioncino@icloud.com (M.L.); limongelligiuseppe@libero.it (G.L.); paolo.calabro@unicampania.it (P.C.)

3 Division of Clinical Cardiology, A.O.R.N. "Sant'Anna e San Sebastiano", 81100 Caserta, Italy

4 Ceinge Biotecnologie Avanzate S. C. a R. L., 80131 Naples, Italy; dargenio@ceinge.unina.it (V.D.); ranieria@ceinge.unina.it (A.R.)

5 Department of Human Sciences and Quality of Life Promotion, San Raffaele Open University, Via di val Cannuta 247, 00166 Roma, Italy

6 Prescient Metabiomics, 1600 Faraday Ave, Carlsbad, CA 9200, USA; gcasaburi@prescientmetabiomics.com

7 Unit of Inherited and Rare Cardiovascular Diseases, Azienda Ospedaliera di Rilievo Nazionale AORN Dei Colli, “V. Monaldi”, 80122 Naples, Italy; fimianifabio@hotmail.it

8 Inherited and Rare Cardiovascular Diseases, Department of Translational Medical Sciences, University of Campania “Luigi Vanvitelli”, Monaldi Hospital, 81100 Naples, Italy; martina.caiazza@yahoo.it

9 Department of Neuroscience and Rehabilitation, Center of Sports Medicine and Disability, AORN, Santobono-Pausillipon, 80122 Naples, Italy; ninodalicandro@libero.it

10 Department of Translational Medical Sciences, University of Naples Federico II, 80131 Naples, Italy; daniela.terracciano@unina.it

11 Task Force on Microbiome Studies, University of Naples Federico II, 80100 Naples, Italy

* Correspondence: gfrisso@unina.it (G.F.); olga.scudiero@unina.it (O.S.); Tel.: +39-3472409595 (G.F.); +39-3396139908 (O.S.)

Abstract: Laboratory medicine, along with genetic investigations in sports medicine, is taking on an increasingly important role in monitoring athletes' health conditions. Acute or intense exercise can result in metabolic imbalances, muscle injuries or reveal cardiovascular disorders. This study aimed to monitor the health status of a basketball player with an integrated approach, including biochemical and genetic investigations and advanced imaging techniques, to shed light on the causes of recurrent syncope he experienced during exercise. Biochemical analyses showed that the athlete had abnormal iron, ferritin and bilirubin levels. Coronary Computed Tomographic Angiography highlighted the presence of an intramyocardial bridge, suggesting this may be the cause of the observed syncopes. The athlete was excluded from competitive activity. In order to understand if this cardiac malformation could be caused by an inherited genetic condition, both array-CGH and whole exome sequencing were performed. Array-CGH showed two intronic deletions involving MACROD2 and COMMD10 genes, which could be related to a congenital heart defect; whole exome sequencing highlighted the genotype compatible with Gilbert syndrome. However, no clear pathogenic mutations related to the patient's cardiological phenotype were detected, even after applying machine learning methods. This case report highlights the importance and the need to provide exhaustive personalized diagnostic work up for the athletes in order to cover the cause of their malaise and for safeguarding their health. This multidisciplinary approach can be useful to create ad personam training and treatments, thus avoiding the appearance of diseases and injuries which, if underestimated, can become irreversible disorders and sometimes can result in the death of the athlete. 
Keywords: athlete; sport activity; laboratory medicine; heart bridge; genomic analysis; exome sequencing; oligogenic combination network

\section{Introduction}

Laboratory medicine and medical genetics have become disciplines necessary for monitoring athletes' health [1-3]. It is known that intense physical activity can cause cardiovascular disorders $[4,5]$, thrombotic events $[6,7]$, muscle damage $[4,8,9]$ and infections [10-13], mostly in predisposed subjects. Consequently, the observation of the health status of competitive athletes is necessary for evaluating the stress induced by intense physical activity. Particularly, laboratory monitoring of athletes helps physicians and athletic trainers in the development of targeted training and recovery programs to reduce injuries and/or permanent damage [1-3,14]. Recently, in order to investigate athletes state of health, the scientific community has identified biomarkers useful as an alarm bell for the protection of the athlete [15] in order to early highlight urinary infections [16], activation of the immune system [17], brain damage [18], muscle injuries [19-21], cardiac disorders [3,22], hormonal $[23,24]$ and vitamin dysregulations $[25,26]$.

In addition, another fundamental aspect for the correct clinical evaluation of athletes includes cardiovascular examination and diagnostic imaging capable of identifying cardiac pathologies that are potentially lethal $[27,28]$ or muscle injuries $[29,30]$, which would be difficult to evaluate at the medical/laboratory examination alone.

At the same time, it is known that some forms of hereditary/congenital heart disease or metabolic defects, which can cause serious accidents such as sudden death, may not be evident in the absence of family history and/or specific symptoms [31,32].

Hence, the need to identify all determinants that can define the phenotype of athletes is becoming clear, shedding light on the metabolic characteristics and the mechanisms of adaptation and response of the individual athlete to the stress caused by intense physical activity.

In this scenario, we present a case report in which a multidisciplinary approach is used to investigate the causes that influenced the health status of a competitive athlete suffering from repeated syncopes. Using biochemical and haematological tests and cardiovascular and genetic investigations, we highlight the injuries that resulted in the player's withdrawal from competitive activity while preserving his life.

\section{Materials and Methods}

\subsection{Ethical Approval}

The study was conducted according to the ethical guidelines of Helsinki Declaration of the World Medical Association and was approved by the ethics committee (protocol 200/17) of the University of Naples Federico II. The athlete provided written consent to carry out biochemical laboratory tests and genetic analysis.

\subsection{Cardiovascular Evaluation}

The cardiovascular evaluation of the athlete included a two-step approach $[33,34]$ :

(1) Standard clinical evaluation, as a part of the pre-participation screening, which consisted of family and personal history, physical examination, electrocardiogram (ECG) and stress test, according to the current recommendations [34];

(2) Additional clinical investigations in the presence of one or more clinical or instrumental markers suggestive of a pathologic condition potentially associated with an increased risk of sudden cardiac death during physical activity. The additional investigations included echocardiography, 24-48 ECG Holter, electrophysiological study, coronary computed tomographic angiogram (CTA) and exercise echocardiogram. 


\subsection{Clinical Laboratory Analysis}

Blood samples of the athlete have been collected in two different phases of the agonistic season: the first blood samples were collected in September (0 month), in the preseason phase, and the second samples were collected in November (1 month after the start of the championship, during an episode of myocardial ischemia). A panel of clinical chemistry, hematology, coagulation and hormonal assays was analysed, which provided a general picture of the athlete's health, providing information regarding metabolic and inflammatory status, hepatic and renal function, iron profile, muscle metabolism, endocrine system and hematological parameters. The blood samples were taken in the morning (8:00 a.m.) before training, after $72 \mathrm{~h}$ of rest. As a safeguard measure, blood, serum and plasma samples were frozen at $-80{ }^{\circ} \mathrm{C}$ in case any analysis had to be repeated. We also collected the urine sample to evaluate $\mathrm{pH}$, specific weight, colour, appearance, presence of proteins, glucose, ketones, bilirubin, hemoglobin, nitrite, leukocyte esterase, bacterial cells, squamous cells, leukocytes and erythrocytes. The urine samples were taken in the morning before training, according to standard procedure. Standard biochemical analyses were performed by using a standard serum analyzer in Architect c16000 (Abbott Diagnostics, Chicago, IL, USA). Red blood cells, leukocytes and platelet counts were performed through the Siemens Advia 2120i (Siemens Healthcare, Munich, Germany, EU) hematology analyzer.

Coagulation analyses were performed according to the manufacturer's recommendation using a standard plasma analyzer ACLTOP550 CTS (Laboratory Company, Inova Diagnostics, Inc. and Biokit, San Diego, CA, USA).

Serum cortisol concentrations were determined by immunoassay procedures through the Immulite 2000 analyzer (Cortisol Immunoassay kit; Siemens Healthiness, Erlangen, Germany); the measurement of vitamin D and thyroid hormones (fT3, fT4 and TSH) was performed by automated enzyme immunoassays in chemiluminescence using Liaison XL (Diasorin, Saluggia, Italy, EU) and ADvia Centaur (Siemens Heltineers, Erlangen, Germany, EU), respectively. All the procedures took place according to the manufacturer's recommendation.

The first morning urine sample was collected and analyzed within four hours of arrival using an automated urine chemistry analyzer (UC3500, Sysmex, Kobe, Japan) and a fluorescence flow cytometer (UF 1000i, Sysmex, Kobe, Japan) according to the manufacturer's instructions. When necessary, we conducted an examination using an optical microscope.

All analysis was performed in triplicate in order to guarantee the accuracy of results.

\subsection{Genetic Test: Array-Comparative Genomic Hybridization}

Genomic DNA was extracted from peripheral venous blood by the Illustra Nucleon Genomic DNA Extraction kit (GE Healthcare, UK). High resolution array-Comparative Genomic Hybridization (a-CGH) analysis was performed according to the manufacturer's protocols. DNA specimen was analyzed with the Human Genome CGH Microarray kit $4 \times 180 \mathrm{~K}$ (Agilent Technologies, Santa Clara, CA, USA), with an average space of $13 \mathrm{~Kb}$, and allowing an average resolution of $25 \mathrm{~Kb}$. The microarray was scanned on an Agilent G2600D scanner. Image files were quantified, and data were visualized by using Agilent's Cytogenomics software (V.4.0.3.12).

\subsection{Genetic Test: Whole Exome Sequencing and DNA Variants Analysis}

A total amount of $1.0 \mu \mathrm{g}$ of genomic DNA, quantified using the Qubit dsDNA BR Assay (Thermo Fisher Scientific, Waltham, MA, USA), was used as input for the following molecular analysis. Exome enrichment was performed by using the Agilent SureSelect Human All ExonV6 kit (Agilent Technologies, Santa Clara, CA, USA), following the manufacturer's recommendations and using a specific index sequence to tag the sample univocally. First, genomic DNA was sheared by a hydrodynamic shearing system (Covaris, Woburn, MA, USA) to obtain 180-280 bp length fragments. Next, fragments ends were blunted through exonuclease/polymerase enzymes, and after a beads-based purification 
step, sequencing adapters were ligated to fragmented ends. The adapted fragments were specifically enriched using the exome probes. The captured library has been purified by using the AMPure XP beads (Beckman Coulter, Beverly, MA, USA), and quality was assessed by using the Agilent high sensitivity DNA assay on the Agilent Bioanalyzer 2100 system (Agilent Technologies, CA, USA). Finally, sequencing was carried out by using Illumina Sequencers, according to the manufacturer's instructions (Novogene Service).

After quality filtering and adapters removal, FASTQ files were mapped against the reference human genome sequence to carry out variants calling by using the Illumina Genome Studio tool. The obtained variant call format (VCF) file was further analyzed by using eVAI software v1.2 (enGenome) to highlight any pathogenetic variant and prioritized variants according to ACMG's guidelines [35].

\subsection{Genetic Test: Prediction of Disease-Causing Variant Combinations and Network Representation}

The VCF file was leveraged to further explore potential disease-causing variant combinations using ORVAL v2019 [36], which works on the GRCh37/hg19 human genome assembly. The first step in ORVAL is a variant filtering procedure in order to select relevant variants. We selected the following filtering parameters: (i) a Minor allele frequency (MAF) threshold of 0.03 [37]; (ii) automatic removal of intergenic variants (i.e., variants that are not inside the defined gene coordinates based on hg19); and (iii) removal of intronic and non-splicing synonymous variants [36]. After the variant filtering step, a prediction step occurs in order to identify candidate disease-causing variant combinations. This step is performed with the Variant Combination Pathogenicity Predictor (VarCoPP) v1.0 tool [38]. VarCoPP uses Random Forest (RF) machine-learning methods to predict the pathogenicity of any bi-locus variant combination. Each predictor of VarCoPP has been trained on the pathogenic variant combinations present in the Digenic Diseases Database (DIDA) [39]. The predicted genes/variant are ranked by Gene Damage Index (GDI) [40]. Additionally, a machine-learning based method was also employed to predict digenic effect $[41,42]$ of a pathogenic digenic variant combination identified and ranked by pathogenicity scores and confidence intervals [38]. For exploration purposes, the predicted oligogenic information was represented with gene networks in ORVAL to explore potential protein-protein interactions (PPI). The PPI network is built from the set of proteins belonging to the selected module by using the ComPPI database v2.1.1 [43]. Within the network, nodes represent genes, and edges connect two genes only if there exists at least one variant combination between them that has been predicted as candidate disease causing with VarCoPP.

\section{Results}

\subsection{Clinical History}

Herein, we report the case of a 19 year old competitive athlete who came to the emergency department for the occurrence of exercise-induced syncope without prodromes. He denied any family history of cardiovascular disease or sudden cardiac death in firstdegree relatives. He was not a smoker and did not report the use of drugs or other medicaments. As advocated by current guidelines $[34,44]$, he had been evaluated during routine pre-participation screening, which were unremarkable. During the examination, he reported a previous transient loss of consciousness at the age of 18, which was not investigated at that time.

At our department, he was conscious, and his vital parameters were within the reference range. Blood pressure and heart rate were measured while supine and during active standing for $3 \mathrm{~min}$, as recommended at initial syncope evaluation [45], in order to exclude orthostatic hypotension. Continuous in-hospital ECG monitoring (Figure 1) did not show abnormalities, with the exclusion of asymptomatic sinus bradycardia. The echocardiographic evaluation showed mild left ventricular hypertrophy (LVH) with normal systolic and diastolic function. Exercise ECG showed enhanced QT dispersion in the absence of 
other abnormalities (Figure 1). Electrophysiologic study was performed; nevertheless, no inducible arrhythmia was detected.

A

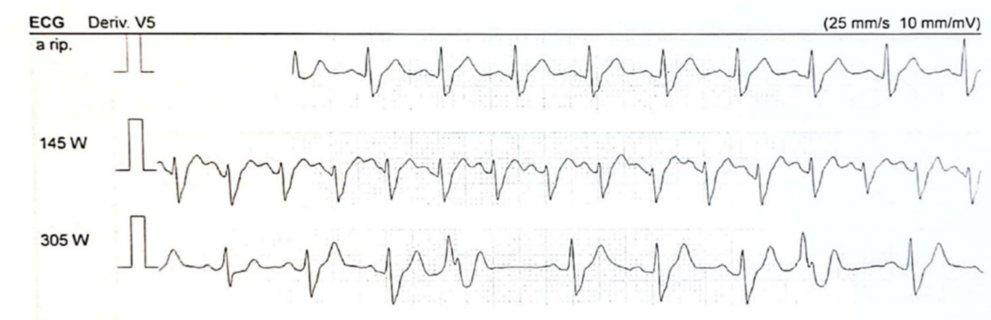

Note di referto

carico submassimale
Carico max: 305 W in Intervallo 8 dopo $15: 23,114 \%$ del teorico 267.5 W, MET: 10.7

Carico max: 305 W in Intervallo 8 dopo $15: 23,114 \%$ del teorico 267.5 W, MET: FC basale: 105, FC max: 174 in Intervallo 6 dopo $12: 00,96 \%$ del teorico 181
ST max in Deriv II: $0.76 \mathrm{mV}$ in Intervallo 7 max sottosliv. ST in Deriv V1: $-0.60 \mathrm{mV}$ in Intervallo
BEV globale: 76, BEV isol.: 61 , Coppia: 6 , Salve: 1

B

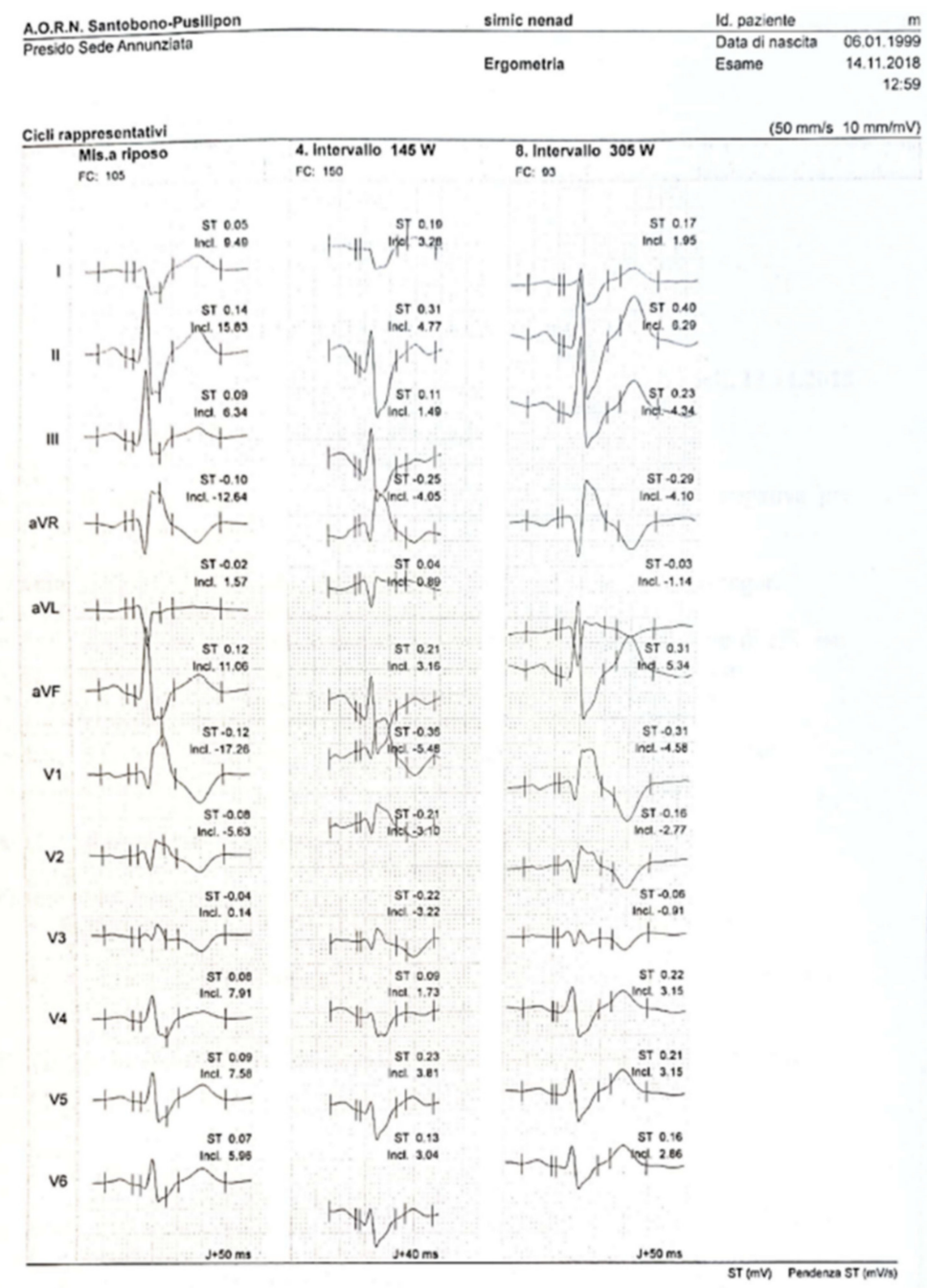

Figure 1. Representative images of the electrocardiogram. (A) Representation of the three electrocardiograms performed, the first at rest (Line 1) and the other two under exercise (Line 2 and 3). (B) Representative ECG cycles taken at rest (column 1) and during exercise (column 2 and 3).

In consideration of the absence of cardiac abnormalities, participation into competitive sport was not discouraged. 
After one year, the athlete experienced another syncopal episode during low-intensity exercise. Pulse assessment revealed tachycardia $(180 \mathrm{bpm})$ that was unrelated to exertion; nevertheless, the patient was conscious and hemodynamically stable. The athlete was admitted to the emergency department, where baseline assessment did not show any abnormalities; however, routine blood samples revealed a slight increase in high sensitivity cardiac troponin (hs-Tn). Based on the concept that the probability of myocardial infarction increases with increasing hs-Tn values, the ESC $0 / 1 \mathrm{~h}$ algorithm to rule out acute coronary syndrome (ACS) was applied. Due to the fact that negative predictive value for patients meeting the "rule out" criteria approaches 99\%, the diagnosis of non-ST-segment elevation myocardial infarction (NSTEMI) was excluded, and tachycardia was suspected to be the cause of myocardial injury.

As a young athlete with mild $\mathrm{LVH}$, cardiac magnetic resonance (CMR) was recommended to exclude possible underlying hypertrophic cardiomyopathy (HCM). At the same time, a blood sample was collected for the re-evaluation of biochemical-clinical and hematological data, as well as to conduct an in-depth genetic study with array-CGH and Whole Exome Sequencing (WES) analysis, which could highlight the presence of genetic variants with a higher risk of sudden cardiac death. However, CMR was not performed due to the patient's refusal to undergo the exam. A coronary computed tomographic angiogram (CTA) was performed to exclude cardiovascular abnormalities and epicardial coronary stenoses.

\subsection{Instrumental Results}

Coronary CTA showed a long superficial bridge $(20 \mathrm{~mm})$ involving the middle segment of the left anterior descending (LAD) artery (Figure 2). In addition, the distal segments of diagonal arteries were involved.

No atherosclerotic lesions were observed. Exercise echocardiogram was performed in order to document the presence of inducible ischemia, with evidence at the maximum heart rate of hypokinesia in antero-septal basal segments, which disappeared after exercise. The athlete received beta-blocker therapy and was withdrawn from competitions.

The opportunity to undergo surgical treatment for the myocardial bridge was considered; nevertheless, due to patient's refusal, surgery was not performed.

\subsection{Clinical Laboratory Analysis}

The patient's hematological and biochemical parameters were all in the reference range (see Table S1), except those shown in Table 1. Particularly, martial homeostasis highlighted a condition of iron deficiency without anemia, which persisted even after two months of oral iron supplementary therapy, as evidenced by low serum ferritin in both samples (see Table 1). Total and indirect bilirubin increased at the first and second samplings, consistent with the known diagnosis of Gilbert's syndrome. Hormones and vitamins levels evaluation underlined vitamin D hypovitaminosis and an aspecific slight elevation of FT3 at the first sampling.

\subsection{Analysis of Array-CGH}

By using array-CGH analysis, we detected a deletion of approximately $107.5 \mathrm{~Kb}$ on the 20 chromosome at p12.1 region (Figure 3), which includes partially intron 5 of MACROD2 gene (RefSeq \# NC_000020.11) and MACROD2-AS1 gene. Furthermore, we identified a deletion of approximately $48.49 \mathrm{~Kb}$ on the 5 chromosome at q23.1 region, partially including the COMMD10 gene (RefSeq \# NC_000005.10) (Figure 3), and a deletion of approximately $38.4 \mathrm{~Kb}$ on the $\mathrm{X}$ chromosome at 13.3 region that partially includes the MIR325HG gene (RefSeq \# NC_000023.11). 
A

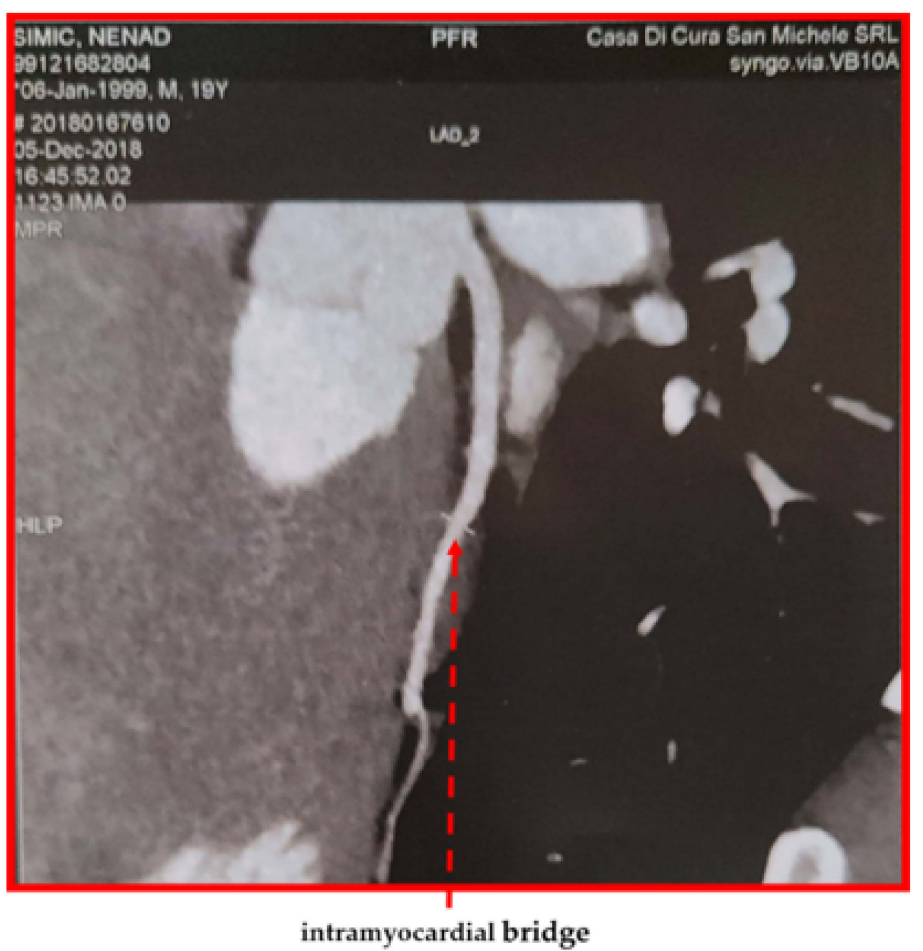

B

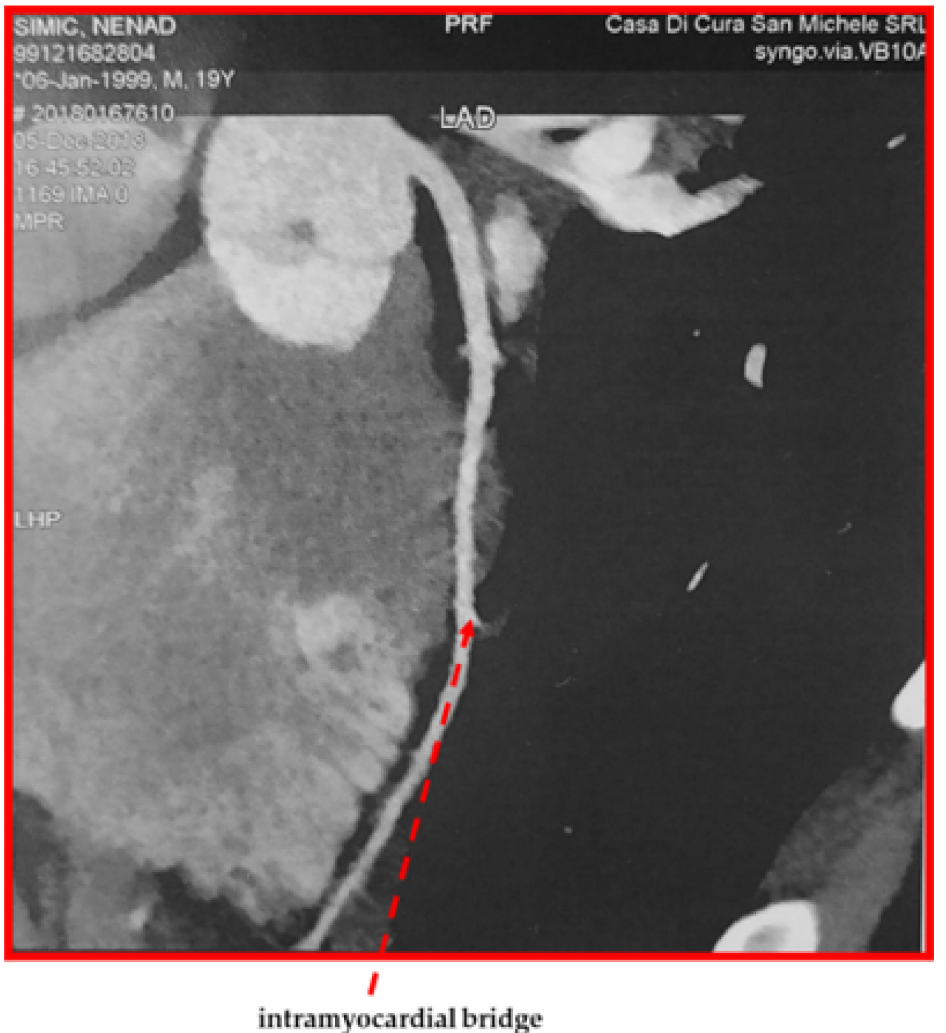

Figure 2. Cont. 
C

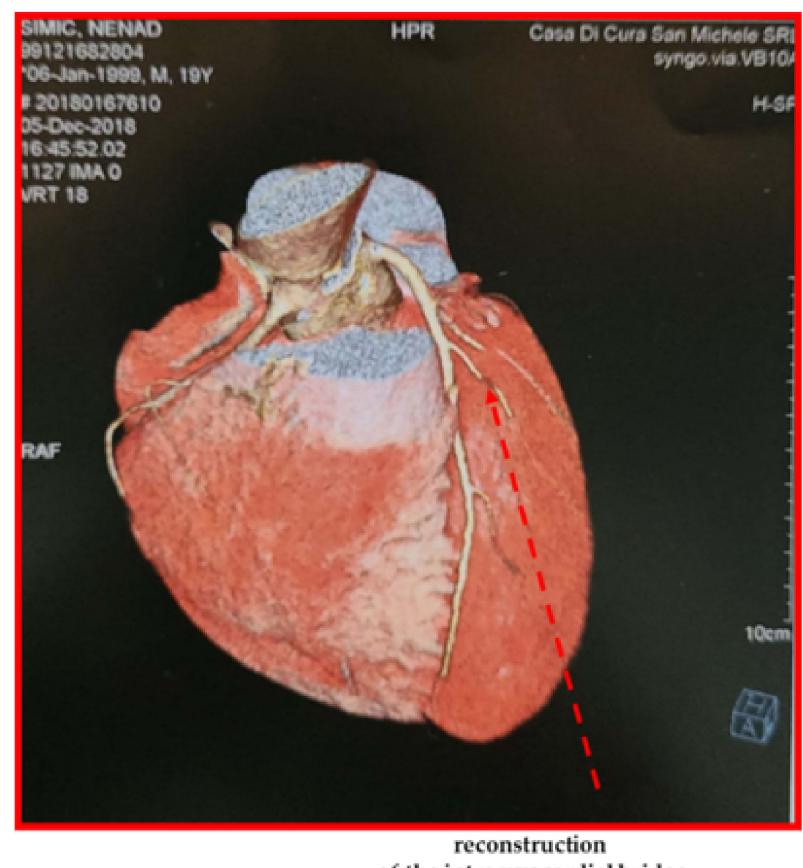

of the intramyocardial bridge

Figure 2. (A,B) Representative images of the intramyocardial bridge. (C) Examination performed with CTA and $128 \times 2$ by gating scanner, dual source, gantry rotation time $280 \mathrm{~ms}$, collimation thickness $0.6 \mathrm{~mm}$, during injection of iodate i.v. with multiplanar reconstruction, cMPR (Multi Planar Reformation), MIP (Maximum Intensity Projection) and 3D volume rendering. Double reading exam. Reference standard for SCCT/SIRM international guidelines.

Table 1. Altered biochemical parameters found in the competitive athlete at time 0 (before the start of the championship) and time 1 (after 2 months from the start of the championship).

\begin{tabular}{ccc}
\hline Reference Values & 0 Month & 2 Month \\
\hline $\begin{array}{c}\text { Iron } \\
(65-175 \mu \mathrm{g} / \mathrm{dL})\end{array}$ & 58 & 119 \\
\hline $\begin{array}{c}\text { UIBC } \\
(69-240 \mu \mathrm{g} / \mathrm{dL})\end{array}$ & 309 & 220 \\
\hline $\begin{array}{c}\text { Ferritin } \\
(22-275 \mathrm{ng} / \mathrm{dL})\end{array}$ & 10 & 10 \\
\hline $\begin{array}{c}\text { Total Bilirubin } \\
(0.2-1.2 \mathrm{mg} / \mathrm{dL})\end{array}$ & 2.2 \\
\hline $\begin{array}{c}\text { Direct Bilirubin } \\
(0-0.5 \mathrm{mg} / \mathrm{dL})\end{array}$ & 1.86 & 0.69 \\
\hline $\begin{array}{c}\text { Vitamin D } \\
(>30 \mathrm{mg} / \mathrm{dL})\end{array}$ & 0.59 & 17.3 \\
\hline $\begin{array}{c}\text { FT3 } \\
(2.3-4.3 \mathrm{pg} / \mathrm{mL})\end{array}$ & 22.7 & 2.5 \\
\hline
\end{tabular}

* Reference values of the Italian Society of Clinical Biochemistry and Clinical Molecular Biology (SIBioC). 

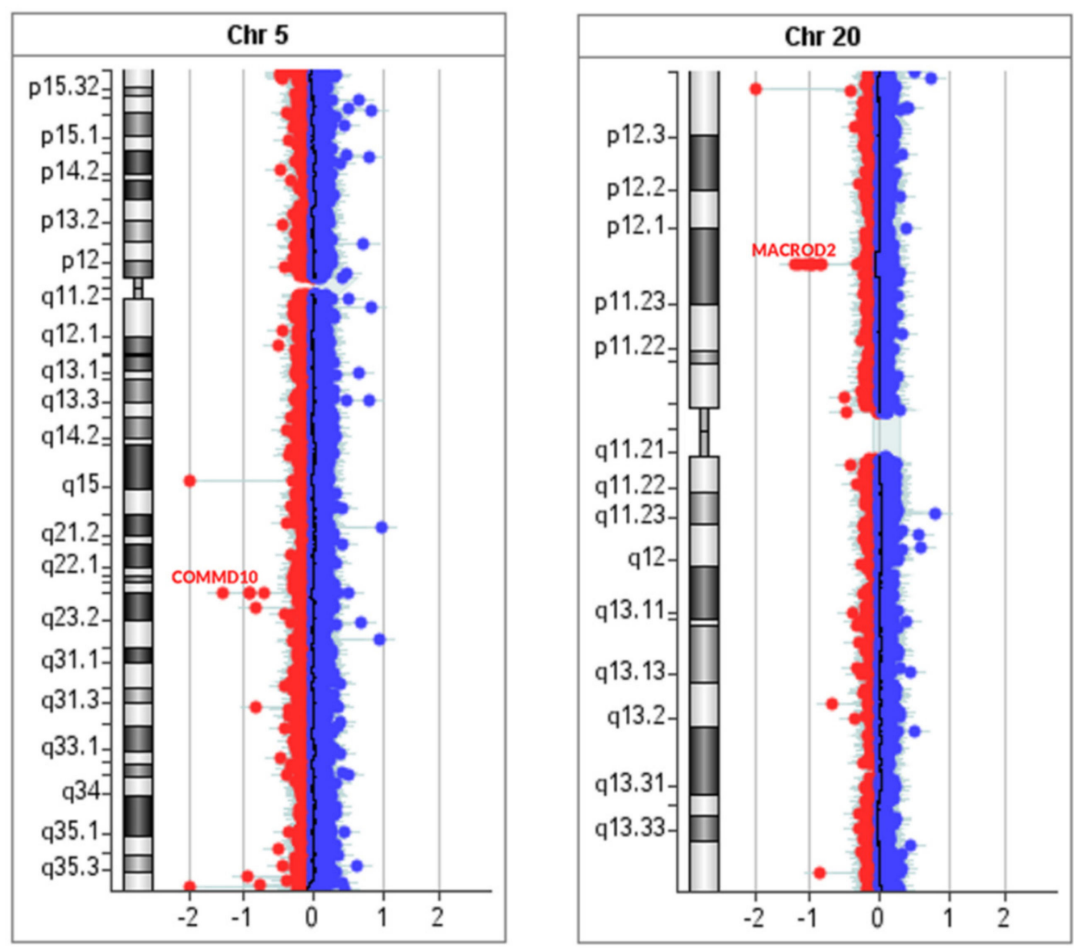

Figure 3. Array-CGH. The CGH analysis shows a heterozygous deletion on the 5 chromosome at q23.1 region, partially including COMMD10 gene (left) and a heterozygous deletion on the 20 chromosome at p12.1 region, partially including MACROD2 and MACROD2-AS1 genes (right).

The CNVs observed in this study were evaluated using the Database of Genomic Variants, the DECIPHER Database and the UCSC Genome Browser.

\subsection{Exome Sequencing}

Whole exome sequencing (WES) was performed in order to identify any pathogenic mutation potentially related to patient's clinical phenotype. In total, $7.4 \mathrm{~Gb}$ was obtained, which is equivalent to more than 49 million reads, $99 \%$ of which passed quality filtering. Variants calling highlighted the presence of 271,966 variants that were further analyzed in order to verify the presence of clinically relevant variants. Variants were filtered based on coverage $(>10 X)$, variant's allele frequency $(>30 \%)$, a pathogenicity score based on ACMG criteria and ClinVar classification according to eVAI interpreter software pipeline.

Considering the pathogenicity score, six variants were identified (see Table S2). All these variants are in a heterozygous state and have been associated to date to autosomal recessive disorders; moreover, no variants have been related to cardiovascular phenotypes.

In addition, another 103 variants were classified according to ClinVar in one of the following categories: pathogenic, likely pathogenic, drug response, association, risk factor, protective, affect and confers sensitivity (see Table S3). However, none of these variants showed an association with the patient's clinical signs. Thus, since exome analysis was not able to identify pathogenic mutations explaining the patient phenotype, we carried out a bioinformatic analysis to verify if the combination of more DNA variants may identify a risk haplotype.

Furthermore, the analysis of the UGT-1A1 gene promoter allowed genotyping the (TA)n polymorphism in the gene TATA box (rs3064744), highlighting that the athlete was heterozygous UGT1A1*1/*28.

\subsection{Pathogenic Variant Predictions and Oligogenic Combination Network}

In addition to ClinVar, a Random Forest (RF) approach was used to predict pathogenic variants using VarCopp. Sixty-five genes were classified with a median pathogenicity score 
$\geq 0.67$ and represented in an interaction network (Figure 4A). A subnetwork for gene pairs carrying a severe pathogenicity score (i.e., $\geq 0.89$ ) was also extrapolated (Figure 4 B), resulting in 12 genes that were ranked based on their Gene Damage Index (GDI) (see Table S4). Seven genes had unknown GDI. The gene with the lowest GDI and, thus, was more susceptible to disease-causing mutations was $F A M 104 B$, which translates to FAM104B (Family With Sequence Similarity 104, Member B). The FAM104B gene, located on chromosome $X$, has currently not clear known function but has been associated with both autistic disorder (PMID:25741868) and syndromic X-linked intellectual disability Lubs type (PMID:21681106; PMID:30208311). The second most susceptible gene to diseasecausing mutation based on GDI score was TBC1D8B (TBC1 Domain Family Member 8B). Diseases associated with TBC1D8B include Nephrotic Syndrome Type 20 (PMID: 30661770) and Genetic Steroid-Resistant Nephrotic Syndrome (PMID: 31732614). Among its related pathways, Clathrin-derived vesicle budding and vesicle-mediated transport are observed.

A

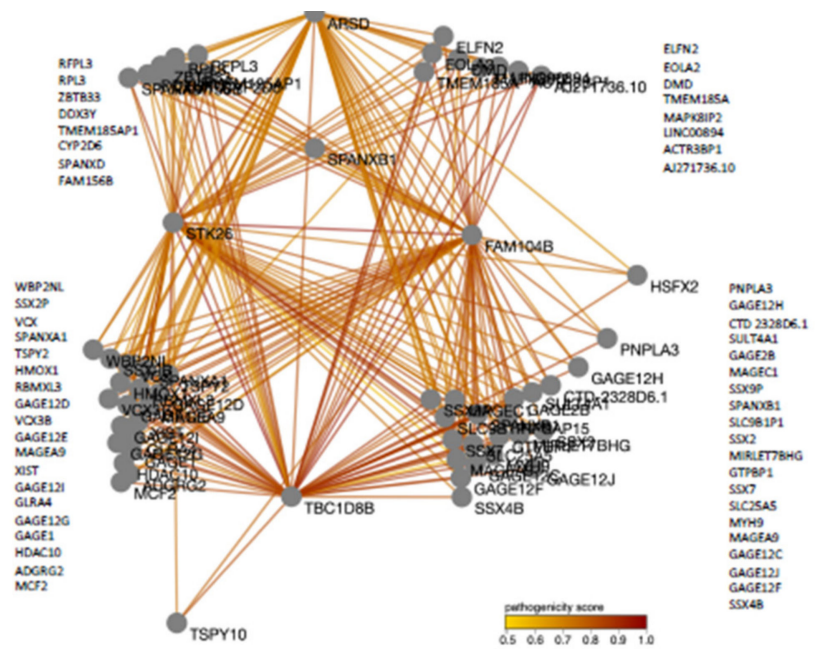

B

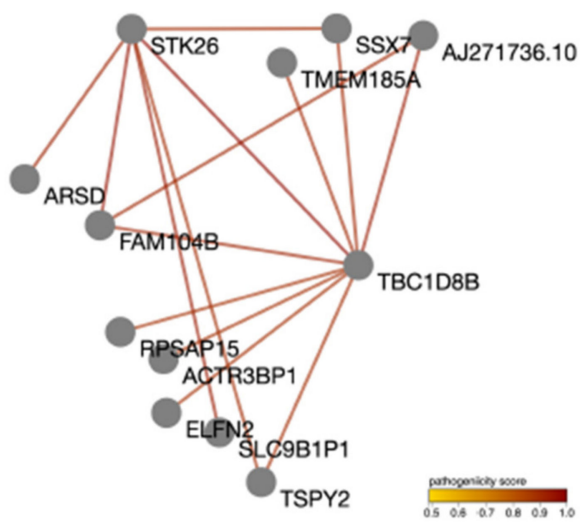

Figure 4. Oligogenic Combination Network. (A). Sixty-five genes had a median pathogenic score of $\geq 0.67$. (B). Subset of network with highest median pathogenic score $(\geq 89)$. Each node in the networks represent a gene reporting a pathogenic variant, while edges connect two genes only when there is at least one candidate disease-causing variant combination as predicted by VarCoPP. The colors of the edge represent the highest pathogenicity score for that pair and, more specifically, the highest Classification Score (CS) computed for a variant combination of that pair. This score is represented in a range from yellow (low pathogenicity score) to dark red (high pathogenicity score).

\section{Discussion}

The use of biochemical, haematological and genetic evaluation to assess risk factors in people who play sports is of growing interest at an amateur, competitive and elite level $[1,3,6,46,47]$. In this case report, we evaluated changes in biochemical, haematological and instrumental cardiovascular parameters and performed in-depth genetic analyses in 
order to shed light on the cause of repeated syncopes in an athlete who appeared to be in apparent good health but suffered from a few episodes of syncope.

First of all, from the biochemical analysis, we highlighted a deficiency in the iron level. Competitive athletes, particularly teenage female athletes, may develop iron deficiency. Regular and above all high-intensity training increases iron losses by as much as $70 \%$ in athletes when compared to sedentary populations due to heavy sweating as well as increased blood loss in the urine and gastrointestinal tract [48]. However, insufficient dietary iron intake may also contribute to iron deficiency in athletes. One of the most sensitive and specific biomarker of iron deficiency is ferritin. Ferritin is the main iron storage protein within cells, and its concentration in blood reflects the extent of the mineral reserves in the body. Although ferritin levels less than $15 \mathrm{ng} / \mathrm{mL}$ are considered diagnostic for iron deficiency in the general population, a reasonable ferritin goal in athletes would be at least $30-40 \mathrm{ng} / \mathrm{mL}$, as they need more iron than less active subjects. Our basketball player showed a condition of iron deficiency without anemia, which required oral iron supplementation and control blood tests after an at least 3-month long treatment. Measurement of Ab anti-transglut IgA (see Table S1) ruled out that he was celiac. The check carried out after two months, following the second syncopal event, shows an improvement of serum iron and unsaturated iron binding capacity (UIBC) parameters, but there was still a significant reduction in iron deposits. The deficiency of iron contributes to cardiac and peripheral muscle dysfunction [49], emerging as a new comorbidity and a therapeutic target of chronic heart failure [49].

At the same time, biochemical investigations revealed that the athlete suffered from Gilbert's syndrome, as evidenced by the condition of hyperbilirubinemia, with an increase in unconjugated bilirubin. Furthermore, sequencing by NGS allowed genotyping the (TA)n polymorphism (rs3064744) in the TATA box of the UGT1A1 gene. TA insertions in the TATA box of the UGT1A1 promoter are associated with hyperbilirubinaemia in Gilbert's patients. Gilbert syndrome is a common hereditary condition characterized by mild hyperbilirubinemia. It is known that common genetic polymorphisms can be associated with the onset of diseases, including cardiovascular ones [50]. An insertional polymorphism of the TATA element upstream relative to UGT1A1 gene results in reduced gene expression level [51]. Sequencing analysis showed that the athlete was heterozygous for UGT1A1*1/*28, which is compatible with the condition of moderate hyperbilirubinemia, and worsened following overexertion.

Moreover, the athlete showed vitamin D deficiency, particularly marked after a month of regular high-intensity training. Several authors indicated that vitamin D insufficiency is common among basketball players [52]. In addition, several reports are available demonstrating that Vitamin D deficiency among athletes was associated with increased Vitamin D receptor expression in skeletal muscles, resulting in high consumption of Vitamin D and low circulating levels $[53,54]$. Finally, the lower levels in the second sample (collected in November) compared to the first one (collected in September) may also be related to significant circannual rhythms of vitamin D [55]. Our findings support the idea that vitamin $\mathrm{D}$ circulating levels might represent a useful biomarker in athletes for assessing muscle activity levels.

In parallel, a slightly elevated FT3 but not of FT4 and TSH at the first sampling was also observed. This finding is in agreement with a previous report on hormonal changes after physique competition and did not reflect a pathological condition [56,57]. Normal serum TSH concentration, which is the most sensitive indicator of thyroid function, suggests an euthyroid status of the athlete [58,59]. We also observed decreased levels of FT3, FT4 and TSH after two months of physical activity. This finding was not surprising if we considered that exercise has an effect on body homeostasis (i.e., skeletal muscles and cardiac activity) involving the hypothalamus-hypophysis-thyroid axis [60]. Indeed, thyroid hormones and TSH levels changes are expected after physical exercise. Unfortunately, data on these variations were inconsistent, and it was difficult to achieve a definitive 
conclusion [61-64]. Thyroid hormone changes in athletes are still a matter of debate and need further investigations to assess their effect on athletes' health status and performance.

Moreover, we found a decrease in serum testosterone in the trained athlete after 8 weeks of physical activity. This finding is in agreement with previous reports, showing that when athletes undergo an exercise program, testosterone significantly reduced regardless of body weight and sport [65-67].

In the meantime, instrumental investigations performed due to syncope episodes revealed the presence of a myocardial bridge. The myocardial bridge (MB) is a congenital abnormality characterized by an intramural course of a coronary artery. It was initially considered a benign condition, because the myocardium constricts the bridged coronary artery during systole, while blood flow occurs mainly during diastole. However, a possible association with myocardial infarction and sudden cardiac death was observed [68,69]. The risk of sudden cardiac death seems to be higher during strenuous physical activity. In particular, in the case of tachycardia, the blood supply of the myocardium becomes more dependent upon the systolic blood flow, which is impaired by the myocardial bridge. As a consequence, in the presence of a long myocardial bridge and prolonged physical activity, myocardial ischemia and exercise-induced life-threatening ventricular arrhythmias can occur. The most recent recommendations on sports cardiology suggest that athletes with $\mathrm{MB}$ and evidence of myocardial ischemia should be restricted from participation in competitive sports and be advised regarding leisure-time activities [70]. Cardiac CTA can provide a non-invasive anatomic assessment for $\mathrm{MB}$ given its high spatial resolution and unique ability to directly visualize coronary arteries, the myocardium, and their relationship. Moreover, it permits excluding concomitant atherosclerotic coronary artery disease and can demonstrate the relationship between the bridged artery and the adjacent branches, which is helpful in surgical planning. What is of importance is that the functional assessment of $\mathrm{MB}$ is required: the stress echocardiography recommended disqualification from competitive sports for ensuring the health and safety of the young athlete. Treatment with beta-blockers was prescribed as first-line therapy in the symptomatic athlete; although there was the indication to carry out surgery, it was not performed due to the patient's refusal.

Finally, we performed an in-depth genetic evaluation by using array-CGH and WES analysis $[71,72]$ to verify the presence of a genetic background related to the patient's cardiological phenotype. The array-CGH showed the presence of CNVs, which may be associated with the presence of congenital heart disorder. Notably, the macrodeletion in the $M A C R O D 2$ gene is worthy of attention. The protein encoded by MACROD2 is a deacetylase involved in removing ADP-ribose from mono-ADP-ribosylated proteins. This gene is frequently involved in patients with complex syndromes. A recent genome-wide association study, including over 4000 patients affected by congenital heart disease and 8000 controls, revealed a statistically significant association between MACROD2 polymorphisms and development of transposition of the great arteries, although the exact mechanisms remain unclear. Furthermore, data from Lahm et al. [73] show the expression of MACROD2 in human embryonic cardiac cells; therefore, the authors speculated that this gene could act as a transcriptional regulator.

Array-CGH analysis of the athlete showed a $\mathrm{CNV}$ alteration also affecting intron 5 of the COMMD10 gene. COMMD10 gene is involved in modulating the activity of the cullin-RING E3 ubiquitin ligase complexes (CRL) and reducing NF-kappa-B activation. In particular, it is known that some members of the family of 10 proteins containing the Murr1 domain of copper metabolism (COMMD) interacted with ENaC (epithelial channel of the sodium). COMMD10 likely contributes to the regulation of ENaC and may also be involved in long-term blood pressure control [74]. Another pioneering work proves that COMMD10 was expressed in endothelial cells and smooth muscle cells of different tissues, assuming that COMMD10 may be closely related to angiogenesis in the embryo stage. In addition, the study revealed that COMMD10 was expressed in the heart, manifesting that it is probably involved in heart development [75]. Thus, we could hypothesize a role for 
both MACROD2 and COMMD10 genes in the developing heart, thereby contributing, at least in part, to the development of congenital heart disorders, including MB.

On the other end, WES analysis was inconclusive, except for the definition of the (TA)n polymorphism in the UGT1A1 gene. Therefore, we applied a machine learning method by using ORVAL v2019, which is a bioinformatic platform for the prediction and exploration of disease-causing oligogenic variant combinations. Recently, machine learning-based classification and prediction tools have been increasingly employed to predict rare genetic diseases, as well as to drive phenotype-informed genetic analysis. Artificial intelligence (AI) approaches have shown robust accuracy in estimating the risk of previously unappreciated genetic variants for common and complex diseases, including cancer and cardiovascular diseases [76,77]. Here, we tested whether machine learning techniques were able to predict underlying genetic conditions from NGS data. While the resulting models did not directly point to any known cardiac genetic conditions, a subnetwork of 12 gene pairs carrying a severe pathogenicity score (i.e., $\geq 0.89$ ) was revealed. Among these, seven genes had unknown GDI, suggesting that the accumulated mutational damage of these genes in the healthy population could not be estimated with the existing data. This limitation is inherent to the field of AI, especially when applied to medicine, as such techniques heavily relies on training datasets such as the 1000 Genome Project database of gene variations [78]. This uncertainty of prediction power in newly introduced data is often caused by insufficient training data or an unbalance between the training and testing dataset distributions. Therefore, the majority of the proposed models usually collapse in the context of generalizability, failing to confirm predicting power in large-scale population studies [79]. This represents a fundamental limitation, making translational science from data to clinically use extremely challenging in the contemporary Big Data era. Nevertheless, recent efforts in combining multiple datasets, improvements in cloud-based computational power and the use of more sophisticated deep learning techniques may result in models that are clinically useful and could be potential tools for identifying hidden biomarkers and regulatory interactions in different disease conditions, making the use of AI a worthwhile effort to explore in genetic research [80].

\section{Conclusions}

In the modern conception of competitive sport, it is necessary to use a multidisciplinary approach to monitor athletes and to assess the stress that intense physical activity can cause.

Therefore, alongside the athlete's medical history, it is now a duty for the sports medical community to combine biochemical and haematological tests that must be supported by instrumental evaluation in order to produce an overview of the athlete's health status. In this scenario, genetic evaluation may have a relevant role when comprehensive clinical, laboratory and instrumental evaluations fail to identify a clear phenotype or to investigate the genetics and pathological mechanisms of a defined pathological condition. This in-depth analysis of the individual athlete can protect the sportsman during his/her competitive career, also contributing to a reduction in athlete's sudden deaths.

In conclusion, our study aims to shed light on how sports medicine and genetics can support physicians and athletic trainers in understanding the athlete's health, and at the same time it may be necessary for the identification of malformations/silent pathologies that could result in irreversible pathological conditions and/or the death of the athlete.

Supplementary Materials: The following are available online at https:/ /www.mdpi.com/article/10 .3390/diagnostics11112144/s1, Table S1: Clinical Laboratory analysis, Table S2: Pathogenic/Likely pathogenic variants identified in the analyzed athlete by WES, Table S3: DNA variants identified by WES and classified according to ClinVar in one of the following categories: pathogenic, likely pathogenic, drug response, association, risk factor, protective, affect, confers sensitivity, Table S4: Top selected genes ranked by Gene Damage Index (GDI). 
Author Contributions: Conceptualization, G.F. and O.S.; investigation, M.B., C.M. (Cristina Mennitti), A.C., E.M., V.D., G.C., C.M. (Cristina Mazzaccara), A.R., F.F., F.B., F.U., M.C., M.L. and G.D.; data curation, M.B., C.M. (Cristina Mennitti), A.C., E.M., V.D., G.C., A.R., F.F., D.T., B.L., G.F. and O.S.; writing-original draft preparation, M.B., A.C., E.M., V.D., G.C., D.T., B.L., G.F. and O.S.; writing-review and editing, M.B., V.D., G.C., D.T., B.L., G.L., P.C., G.F. and O.S.; visualization, G.F. and O.S.; supervision, G.F. and O.S. All authors have read and agreed to the published version of the manuscript.

Funding: From the Department of Translational Medical Sciences funds from Paolo Calabrò.

Institutional Review Board Statement: The study was conducted according to the ethical guidelines of Helsinki Declaration of the World Medical Association and was approved by the ethics committee (protocol 200/17) of the University of Naples Federico II. The athlete provided written consent to carry out biochemical laboratory tests and genetic analysis.

Informed Consent Statement: Informed consent was obtained from all subjects involved in the study.

Conflicts of Interest: The authors declare no conflict of interest.

\section{References}

1. Lombardo, B.; Izzo, V.; Terracciano, D.; Ranieri, A.; Mazzaccara, C.; Fimiani, F.; Cesaro, A.; Gentile, L.; Leggiero, E.; Pero, R.; et al. Laboratory medicine: Health evaluation in elite athletes. Clin. Chem. Lab. Med. 2019, 57, 1450-1473. [CrossRef] [PubMed]

2. Clénin, G.E.; Cordes, M. Laboratory analyses in sports medicine. Ther. Umsch. 2015, 72, 311-319. [CrossRef] [PubMed]

3. Detta, N.; Frisso, G.; Limongelli, G.; Marzullo, M.; Calabrò, R.; Salvatore, F. Genetic analysis in a family affected by sick sinus syndrome may reduce the sudden death risk in a young aspiring competitive athlete. Int. J. Cardiol. 2014, 170, e63-e65. [CrossRef] [PubMed]

4. Mennitti, C.; Brancaccio, M.; Gentile, L.; Ranieri, A.; Terracciano, D.; Cennamo, M.; La Civita, E.; Liotti, A.; D'Alicandro, G.; Mazzaccara, C.; et al. Athlete's Passport: Prevention of Infections, Inflammations, Injuries and Cardiovascular Diseases. J. Clin. Med. 2020, 9, 2540. [CrossRef] [PubMed]

5. Barretta, F.; Mirra, B.; Monda, E.; Caiazza, M.; Lombardo, B.; Tinto, N.; Scudiero, O.; Frisso, G.; Mazzaccara, C. The Hidden Fragility in the Heart of the Athletes: A Review of Genetic Biomarkers. Int. J. Mol. Sci. 2020, 21, 6682. [CrossRef]

6. Scudiero, O.; Gentile, L.; Ranieri, A.; Coppola, E.; Di Micco, P.; Mazzaccara, C.; D’alicandro, G.; Leggiero, E.; Frisso, G.; Pastore, L.; et al. Physical Activity and Thrombophilic Risk in a Short Series. J. Blood Med. 2020, 11, 39-42. [CrossRef] [PubMed]

7. Hull, C.M.; Harris, J.A. Venous Thromboembolism and Marathon Athletes. Circulation 2013, 128, e469-e471. [CrossRef]

8. Ragozzino, E.; Brancaccio, M.; Di Costanzo, A.; Scalabrì, F.; Andolfi, G.; Wanderlingh, L.G.; Patriarca, E.J.; Minchiotti, G.; Altamura, S.; Summa, V.; et al. 6-Bromoindirubin-3'-oxime intercepts GSK3 signaling to promote and enhance skeletal muscle differentiation affecting miR-206 expression in mice. Sci. Rep. 2019, 9, 18091. [CrossRef]

9. Poor, A.E.; Roedl, J.B.; Zoga, A.C.; Meyers, W.C. Core Muscle Injuries in Athletes. Curr. Sports Med. Rep. 2018, 17, 54-58. [CrossRef]

10. Brancaccio, M.; Mennitti, C.; Laneri, S.; Franco, A.; De Biasi, M.G.; Cesaro, A.; Fimiani, F.; Moscarella, E.; Gragnano, F.; Mazzaccara, C.; et al. Methicillin-Resistant Staphylococcus aureus: Risk for General Infection and Endocarditis among Athletes. Antibiotics 2020, 9, 332. [CrossRef]

11. Scudiero, O.; Brancaccio, M.; Mennitti, C.; Laneri, S.; Lombardo, B.; De Biasi, M.G.; De Gregorio, E.; Pagliuca, C.; Colicchio, R.; Salvatore, P.; et al. Human Defensins: A Novel Approach in the Fight against Skin Colonizing Staphylococcus aureus. Antibiotics 2020, 9, 198. [CrossRef] [PubMed]

12. Scudiero, O.; Lombardo, B.; Brancaccio, M.; Mennitti, C.; Cesaro, A.; Fimiani, F.; Gentile, L.; Moscarella, E.; Amodio, F.; Ranieri, A.; et al. Exercise, Immune System, Nutrition, Respiratory and Cardiovascular Diseases during COVID-19: A Complex Combination. Int. J. Environ. Res. Public Health 2021, 18, 904. [CrossRef] [PubMed]

13. Laneri, S.; Brancaccio, M.; Mennitti, C.; De Biasi, M.G.; Pero, M.E.; Pisanelli, G.; Scudiero, O.; Pero, R. Antimicrobial Peptides and Physical Activity: A Great Hope against COVID 19. Microorganisms 2021, 9, 1415. [CrossRef]

14. Brancaccio, M.; Mennitti, C.; Cesaro, A.; Fimiani, F.; Moscarella, E.; Caiazza, M.; Gragnano, F.; Ranieri, A.; D'Alicandro, G.; Tinto, N.; et al. Dietary Thiols: A Potential Supporting Strategy against Oxidative Stress in Heart Failure and Muscular Damage during Sports Activity. Int. J. Environ. Res. Public Health 2020, 17, 9424. [CrossRef]

15. Lee, E.C.; Fragala, M.S.; Kavouras, S.A.; Queen, R.M.; Pryor, J.L.; Casa, D.J. Biomarkers in Sports and Exercise: Tracking Health, Performance, and Recovery in Athletes. J. Strength Cond. Res. 2017, 31, 2920-2937. [CrossRef]

16. Pero, R.; Brancaccio, M.; Mennitti, C.; Gentile, L.; Arpino, S.; De Falco, R.; Leggiero, E.; Ranieri, A.; Pagliuca, C.; Colicchio, R.; et al. Urinary Biomarkers: Diagnostic Tools for Monitoring Athletes' Health Status. Int. J. Environ. Res Public Health 2020, 17, 6065. [CrossRef] 
17. Pero, R.; Brancaccio, M.; Mennitti, C.; Gentile, L.; Franco, A.; Laneri, S.; De Biasi, M.G.; Pagliuca, C.; Colicchio, R.; Salvatore, P.; et al. HNP-1 and HBD-1 as Biomarkers for the Immune Systems of Elite Basketball Athletes. Antibiotics 2020, 9, 306. [CrossRef] [PubMed]

18. Papa, L.; Ramia, M.M.; Edwards, D.; Johnson, B.D.; Slobounov, S.M. Systematic Review of Clinical Studies Examining Biomarkers of Brain Injury in Athletes after Sports-Related Concussion. J. Neurotrauma 2015, 32, 661-673. [CrossRef] [PubMed]

19. Shin, K.A.; Parkm, K.D.; Ahn, J.; Park, Y.B.; Kim, Y.J. Comparison of Changes in Biochemical Markers for Skeletal Muscles; Hepatic Metabolism; and Renal Function after Three Types of Long-distance Running: Observational Study. Medicine 2016, 95, e3657. [CrossRef] [PubMed]

20. Djaoui, L.; Haddad, M.; Chamari, K.; Dellal, A. Monitoring training load and fatigue in soccer players with physiological markers. Physiol. Behav. 2017, 181, 86-94. [CrossRef]

21. Brancaccio, P.; Maffulli, N.; Limongelli, F.M. Creatine kinase monitoring in sport medicine. Br. Med. Bull. 2007, 81, 209-230. [CrossRef]

22. Girolami, F.; Frisso, G.; Benelli, M.; Crotti, L.; Iascone, M.; Mango, R.; Mazzaccara, C.; Pilichou, K.; Arbustini, E.; Tomberli, B.; et al. Contemporary genetic testing in inherited cardiac disease: Tools; ethical issues; and clinical applications. J. Cardiovasc. Med. 2018, 19, 1-11. [CrossRef] [PubMed]

23. Kraemer, W.J.; Ratamess, N.A.; Hymer, W.C.; Nindl, B.C.; Fragala, M.S. Growth Hormone(s), Testosterone, Insulin-Like Growth Factors, and, Cortisol: Roles and Integration for Cellular Development and Growth With Exercise. Front. Endocrinol. 2020, 11, 33. [CrossRef] [PubMed]

24. Barbara, M.; Anna, K.; Agnieszka, Z.L. The Impact of Professional Sports Activity on GH-IGF-I Axis in Relation to Testosterone Level. Am. J. Mens. Health 2020, 14. [CrossRef]

25. Abrams, G.D.; Feldman, D.; Safran, M.R. Effects of Vitamin D on Skeletal Muscle and Athletic Performance. J. Am. Acad. Orthop. Surg. 2018, 26, 278-285. [CrossRef]

26. Owens, D.J.; Allison, R.J.; Close, G.L. Vitamin D and the Athlete: Current Perspectives and New Challenges. Sports Med. 2018, 48 (Suppl. 1), 3-16. [CrossRef] [PubMed]

27. Fogante, M.; Agliata, G.; Basile, M.C.; Compagnucci, P.; Volpato, G.; Falanga, U.; Stronati, G.; Guerra, F.; Vignale, D.; Esposito, A.; et al. Cardiac Imaging in Athlete's Heart: The Role of the Radiologist. Medicina 2021, 57, 455. [CrossRef] [PubMed]

28. De Innocentiis, C.; Ricci, F.; Khanji, M.Y.; Aung, N.; Tana, C.; Verrengia, E.; Petersen, S.E.; Gallina, S. Athlete's Heart: Diagnostic Challenges and Future Perspectives. Sports Med. 2018, 48, 2463-2477. [CrossRef] [PubMed]

29. Thorborg, K.; Reiman, M.P.; Weir, A.; Kemp, J.L.; Serner, A.; Mosler, A.B.; Hölmich, P. Clinical Examination; Diagnostic Imaging; and Testing of Athletes With Groin Pain: An Evidence-Based Approach to Effective Management. J. Orthop. Sports Phys. Ther. 2018, 4, 239-249. [CrossRef] [PubMed]

30. Justin, W.; Arner, J.W.; Li, R.; Disantis, A.; Zuckerbraun, B.S.; Mauro, C.S. Evaluation and treatment of groin pain syndromes in athletes. Ann. Jt. 2020, 5, 17.

31. Coris, E.E.; Moran, B.K.; De Cuba, R.; Farrar, T.; Curtis, A.B. Left ventricular non-compaction in athletes: To play or not to play. Sports Med. 2016, 46, 1249-1259. [CrossRef]

32. Limongelli, G.; Nunziato, M.; D’Argenio, V.; Esposito, M.V.; Monda, E.; Mazzaccara, C.; Caiazza, M.; D’Aponte, A.; D’Andrea, A.; Bossone, E.; et al. Yield and clinical significance of genetic screening in elite and amateur athletes. Eur. J. Prev. Cardiol. 2020, 2, 1081-1090. [CrossRef] [PubMed]

33. Limongelli, G.; Monda, E.; Nunziato, M.; Salvatore, F. Genetic evaluation in athletes and cascade family screening: Reply. Eur. J. Prev. Cardiol. 2021, 22, zwaa150. [CrossRef] [PubMed]

34. Mont, L.; Pelliccia, A.; Sharma, S.; Biffi, A.; Borjesson, M.; Brugada Terradellas, J.; Carré, F.; Guasch, E.; Heidbuchel, H.; La Gerche, A.; et al. Pre-participation cardiovascular evaluation for athletic participants to prevent sudden death: Position paper from the EHRA and the EACPR; branches of the ESC. Endorsed by APHRS; HRS; and SOLAECE. Eur. J. Prev. Cardiol. 2017, 24, 41-69. [CrossRef]

35. Richards, S.; Aziz, N.; Bale, S.; Bick, D.; Das, S.; Gastier-Foster, J.; Grody, W.W.; Hegde, M.; Lyon, E.; Spector, E.; et al. Standards and guidelines for the interpretation of sequence variants: A joint consensus recommendation of the American College of Medical Genetics and Genomics and the Association for Molecular Pathology. Genet. Med. 2015, 17, 405-424. [CrossRef]

36. Renaux, A.; Papadimitriou, S.; Versbraegen, N.; Nachtegael, C.; Boutry, S.; Nowé, A.; Smits, G.; Lenaerts, T. ORVAL: A novel platform for the prediction and exploration of disease-causing oligogenic variant combinations. Nucleic Acids Res. 2019, 47, W93-W98. [CrossRef] [PubMed]

37. Bomba, L.; Walter, K.; Soranzo, N. The impact of rare and low-frequency genetic variants in common disease. Genome Biol. 2017, 18, 77. [CrossRef]

38. Papadimitriou, S.; Gazzo, A.; Versbraegen, N.; Nachtegael, C.; Aerts, J.; Moreau, Y.; Van Dooren, S.; Nowé, A.; Smits, G.; Lenaerts, T. Predicting disease-causing variant combinations. Proc. Natl. Acad. Sci. USA 2019, 116, 11878-11887. [CrossRef] [PubMed]

39. Gazzo, A.M.; Daneels, D.; Cilia, E.; Bonduelle, M.; Abramowicz, M.; Van Dooren, S.; Smits, G.; Lenaerts, T. DIDA: A curated and annotated digenic diseases database. Nucleic Acids Res. 2016, 44, D900-D907. [CrossRef] [PubMed]

40. Itan, Y.; Shang, L.; Boisson, B.; Patin, E.; Bolze, A.; Moncada-Vélez, M.; Scott, E.; Ciancanelli, M.J.; Lafaille, F.G.; Markle, J.G.; et al. The human gene damage index as a gene-level approach to prioritizing exome variants. Proc. Natl. Acad. Sci. USA 2015, 112, 13615-13620. [CrossRef] [PubMed] 
41. Versbraegen, N.; Fouché, A.; Nachtegael, C.; Papadimitriou, S.; Gazzo, A.; Smits, G.; Lenaerts, T. Using game theory and decision decomposition to effectively discern and characterise bi-locus diseases. Artif. Intell. Med. 2019, 99, 101690. [CrossRef] [PubMed]

42. Gazzo, A.; Raimondi, D.; Daneels, D.; Moreau, Y.; Smits, G.; Van Dooren, S.; Lenaerts, T. Understanding mutational effects in digenic diseases. Nucleic Acids Res. 2017, 45, e140. [CrossRef] [PubMed]

43. Veres, D.V.; Gyurkó, D.M.; Thaler, B.; Szalay, K.Z.; Fazekas, D.; Korcsmáros, T.; Csermely, P. ComPPI: A cellular compartmentspecific database for protein-protein interaction network analysis. Nucleic Acids Res. 2015, 43, D485-D493. [CrossRef]

44. Corrado, D.; Pelliccia, A.; Bjørnstad, H.H.; Vanhees, L.; Biffi, A.; Borjesson, M.; Panhuyzen-Goedkoop, N.; Deligiannis, A.; Solberg, E.; Dugmore, D.; et al. Cardiovascular pre-participation screening of young competitive athletes for prevention of sudden death: Proposal for a common European protocol. Consensus Statement of the Study Group of Sport Cardiology of the Working Group of Cardiac Rehabilitation and Exercise Physiology and the Working Group of Myocardial and Pericardial Diseases of the European Society of Cardiology. Eur. Heart J. 2005, 26, 516-524. [PubMed]

45. Brignole, M.; Moya, A.; de Lange, F.J.; Deharo, J.C.; Elliott, P.M.; Fanciulli, A.; Fedorowski, A.; Furlan, R.; Kenny, R.A.; Martín, A.; et al. 2018 ESC Guidelines for the diagnosis and management of syncope. Eur. Heart J. 2018, 39, 1883-1948. [CrossRef]

46. Šupak-Smolčić, V.; Antončić, D.; Ožanić, D.; Vladilo, I.; Bilić-Zulle, L. Influence of a prolonged fasting and mild activity on routine laboratory tests. Clin. Biochem. 2015, 48, 85-88. [CrossRef]

47. Lombardo, B.; D’Argenio, V.; Monda, E.; Vitale, A.; Caiazza, M.; Sacchetti, L.; Pastore, L.; Limongelli, G.; Frisso, G.; Mazzaccara, C. Genetic analysis resolves differential diagnosis of a familial syndromic dilated cardiomyopathy: A new case of Alström syndrome. Mol. Genet. Genom. Med. 2020, 8, e1260. [CrossRef]

48. Woolf, K.; St Thomas, M.M.; Hahn, N.; Vaughan, L.A.; Carlson, A.G.; Hinton, P. Iron status in highly active and sedentary young women. Int. J. Sport Nutr. Exerc. Metab. 2009, 1, 519-535. [CrossRef] [PubMed]

49. Cohen-Solal, A.; Leclercq, C.; Deray, G.; Lasocki, S.; Zambrowski, J.J.; Mebazaa, A.; de Groote, P.; Damy, T.; Galinier, M. Iron deficiency: An emerging therapeutic target in heart failure. Heart 2014, 100, 1414-1420. [CrossRef] [PubMed]

50. Mazzaccara, C.; Limongelli, G.; Petretta, M.; Vastarella, R.; Pacileo, G.; Bonaduce, D.; Salvatore, F.; Frisso, G. A common polymorphism in the SCN5A gene is associated with dilated cardiomyopathy. J. Cardiovasc. Med. 2018, 19, 344-350. [CrossRef] [PubMed]

51. Skierka, J.M.; Kotzer, K.E.; Lagerstedt, S.A.; O'Kane, D.J.; Baudhuin, L.M.J. UGT1A1 genetic analysis as a diagnostic aid for individuals with unconjugated hyperbilirubinemia. J. Pediatr. 2013, 6, 1146-1152. [CrossRef] [PubMed]

52. Stojanović, E.; Radovanović, D.; Hew-Butler, T.; Hamar, D.; Jakovljević, V. Vitamin D in Basketball Players: Current Evidence and Future Directions. Sports Health 2021, 4. [CrossRef]

53. Hamilton, B. Vitamin D and human skeletal muscle. Scand. J. Med. Sci. Sport. 2010, 20, 182-190. [CrossRef] [PubMed]

54. Gordon-thomson, C.; Tongkao-on, W.; Mason, R.S. Vitamin D and its role in. Curr. Opin. Clin. Nutr. Metab. Care 2001, 12, 165-184.

55. Lombardi, G.; Vitale, J.A.; Logoluso, S.; Logoluso, G.; Cocco, N.; Cocco, G.; Banfi, G. Circannual rhythm of plasmatic vitamin D levels and the association with markers of psychophysical stress in a cohort of Italyn professional soccer players. Chronobiol. Int. 2017, 34, 471-479. [CrossRef] [PubMed]

56. Longstrom, J.M.; Colenso-Semple, L.M.; Waddell, B.J.; Mastrofini, G.; Trexler, E.T.; Campbell, B.I. Physiological; Psychological and Performance-Related Changes Following Physique Competition: A Case-Series. J. Funct. Morphol. Kinesiol. 2020, 5, 27. [CrossRef] [PubMed]

57. Larson-Meyer, D.E.; Gostas, D.E. Thyroid Function and Nutrient Status in the Athlete. Curr. Sports Med. Rep. 2020, 19, 84-94. [CrossRef] [PubMed]

58. Garber, J.R.; Cobin, R.H.; Gharib, H.; Hennessey, J.V.; Klein, I.; Mechanick, J.I.; Pessah-Pollack, R.; Singer, P.A.; Woeber, K.A.; American Association of Clinical Endocrinologists and American Thyroid Association Taskforce on Hypothyroidism in Adults. Clinical practice guidelines for hypothyroidism in adults: Cosponsored by the American Association of Clinical Endocrinologists and the American Thyroid Association. Endocr. Pract. 2012, 18, 988-1028. [CrossRef]

59. Ross, D.S. Laboratory Assessment of Thyroid Function; Wolters Kluwer; UpToDate, Inc.: Waltham, MA, USA, 2017.

60. Babić Leko, M.; Gunjača, I.; Pleić, N.; Zemunik, T. Environmental Factors Affecting Thyroid-Stimulating Hormone and Thyroid Hormone Levels. Int. J. Mol. Sci. 2021, 22, 6521. [CrossRef] [PubMed]

61. Huang, W.S.; Yu, M.D.; Lee, M.S.; Cheng, C.Y.; Yang, S.P.; Chin, H.M.L.; Wu, S.Y. Effect of treadmill exercise on circulating thyroid hormone measurements. Med. Princ. Pract. 2004, 13, 15-19. [CrossRef]

62. Benso, A.; Broglio, F.; Aimaretti, G.; Lucatello, B.; Lanfranco, F.; Ghigo, E.; Grottoli, S. Endocrine and metabolic responses to extreme altitude and physical exercise in climbers. Eur. J. Endocrinol. 2007, 157, 733-740. [CrossRef] [PubMed]

63. Altaye, K.Z.; Mondal, S.; Legesse, K.; Abdulkedir, M. Effects of aerobic exercise on thyroid hormonal change responses among adolescents with intellectual disabilities. BMJ Open Sport Exerc. Med. 2019, 5, 524. [CrossRef]

64. Ciloglu, F.; Peker, I.; Pehlivan, A.; Karacabey, K.; Ilhan, N.; Sayglin, O.; Ozmerdivenli, R. Exercise intensity and its effects on thyroid hormones. Neuro Endocrinol. Lett. 2005, 26, 830-834.

65. Moro, T.; Tinsley, G.; Bianco, A.; Marcolin, G.; Pacelli, Q.F.; Battaglia, G.; Palma, A.; Gentil, P.; Neri, M.; Paoli, A. Effects of eight weeks of time-restricted feeding (16/8) on basal metabolism; maximal strength; body composition; inflammation; and cardiovascular risk factors in resistance-trained males. J. Transl. Med. 2016, 14, 290. [CrossRef] 
66. Stratton, M.T.; Tinsley, G.M.; Alesi, M.G.; Hester, G.M.; Olmos, A.A.; Serafini, P.R.; Modjeski, A.S.; Mangine, G.T.; King, K.; Savage, S.N.; et al. Four Weeks of Time-Restricted Feeding Combined with Resistance Training Does Not Differentially Influence Measures of Body Composition; Muscle Performance; Resting Energy Expenditure; and Blood Biomarkers. Nutrients. 2020, 12, 1126. [CrossRef] [PubMed]

67. Narla, A.; Kaiser, K.; Tannock, L.R. Extremely low testosterone due to relative energy deficiency in sport: A case report. AACE Clin. Case Rep. 2018, 5, e129-e131. [CrossRef] [PubMed]

68. Hostiuc, S.; Rusu, M.C.; Hostiuc, M.; Negoi, R.I.; Negoi, I. Cardiovascular consequences of myocardial bridging: A meta-analysis and meta-regression. Sci. Rep. 2017, 7, 14644. [CrossRef] [PubMed]

69. Corrado, D.; Thiene, G.; Cocco, P.; Frescura, C. Non-atherosclerotic coronary artery disease and sudden death in the young. Br. Heart J. 1992, 68, 601-607. [CrossRef] [PubMed]

70. Pelliccia, A.; Sharma, S.; Gati, S.; Back, M.; Borjesson, M.; Caselli, S.; Collet, J.P.; Corrado, D.; Drezner, J.A.; Halle, M.; et al. 2020 ESC Guidelines on sports cardiology and exercise in patients with cardiovascular disease. Eur. Heart J. 2021, 42, 17-96. [CrossRef] [PubMed]

71. Sanna, V.; Ceglia, C.; Tarsitano, M.; Lombardo, B.; Coppola, A.; Zarrilli, F.; Castaldo, G.; Di Minno, G. Aberrant F8 gene intron 1 inversion with concomitant duplication and deletion in a severe hemophilia A patient from Southern Italy. J. Thromb. Haemost. 2013, 11, 195-197. [CrossRef] [PubMed]

72. Iossa, S.; Costa, V.; Corvino, V.; Auletta, G.; Barruffo, L.; Cappellani, S.; Ceglia, C.; Cennamo, G.; D’Adamo, A.P.; D’Amico, A.; et al. Phenotypic and genetic characterization of a family carrying two Xq21.1-21.3 interstitial deletions associated with syndromic hearing loss. Mol. Cytogenet. 2015, 8, 18. [CrossRef] [PubMed]

73. Lahm, H.; Jia, M.; Dreßen, M.; Wirth, F.; Puluca, N.; Gilsbach, R.; Keavney, B.D.; Cleuziou, J.; Beck, N.; Bondareva, O.; et al. Congenital heart disease risk loci identified by genome-wide association study in European patients. J. Clin. Investig. 2021, 131, e141837. [CrossRef] [PubMed]

74. Ware, A.W.; Cheung, T.T.; Rasulov, S.; Burstein, E.; McDonald, F.J. Epithelial NaC Channel: Reciprocal Control by COMMD10 and Nedd4-2. Front. Physiol. 2018, 9, 793. [CrossRef] [PubMed]

75. Fan, Y.; Zhang, L.; Sun, Y.; Yang, M.; Wang, X.; Wu, X.; Huang, W.; Chen, L.; Pan, S.; Guan, J. Expression profile and bioinformatics analysis of COMMD10 in BALB/C mice and human. Cancer Gene Ther. 2020, 27, 216-225. [CrossRef]

76. Schlieben, L.D.; Prokisch, H.; Yépez, V.A. How Machine Learning and Statistical Models Advance Molecular Diagnostics of Rare Disorders via Analysis of RNA Sequencing Data. Front. Mol. Biosci. 2021, 8, 647277. [CrossRef] [PubMed]

77. Krittanawong, C.; Virk, H.U.H.; Bangalore, S.; Wang, Z.; Johnson, K.W.; Pinotti, R.; Zhang, H.; Kaplin, S.; Narasimhan, B.; Kitai, T.; et al. Machine learning prediction in cardiovascular diseases: A meta-analysis. Sci. Rep. 2020, 10, 16057. [CrossRef]

78. 1000 Genomes Project Consortium; Auton, A.; Brooks, L.D.; Durbin, R.M.; Garrison, E.P.; Kang, H.M.; Korbel, J.O.; Marchini, J.L.; McCarthy, S.; McVean, G.A.; et al. A global reference for human genetic variation. Nature 2015, 526, 68-74.

79. Ghassemi, M.; Naumann, T.; Schulam, P.; Beam, A.L.; Chen, I.Y.; Ranganath, R. A Review of Challenges and Opportunities in Machine Learning for Health. AMIA Jt. Summits Transl. Sci. Proc. 2020, 2020, 191-200. [PubMed]

80. Koumakis, L. Deep learning models in genomics; are we there yet? Comput. Struct. Biotechnol. J. 2020, 18, 1466-1473. [CrossRef] 